\title{
$O$ custo da infraestrutura urbana: um delineamento para $o$ desenvolvimento de pequenos municípios
}

$\mathrm{Na}$ atualidade, o crescimento físico das cidades está relacionado ao aumento econômico e demográfico, que por sua vez, está conexo a expansão do perímetro urbano por meio de desmembramento de áreas rurais como os loteamentos. Esse crescimento gera um custo de infraestrutura urbana que pode refletir de forma acentuada na gestão pública e no desenvolvimento de pequenos municípios. A pesquisa propõe identificar quais são os sistemas de infraestrutura urbana que mais impactam no orçamento da gestão dos pequenos municípios. Como método temos a pesquisa documental, entrevista, orçamentação, observação e do levantamento técnico. A técnica de análise e interpretação de dados buscou apresentar uma discussão dos dados coletados e a aplicabilidade do estudo para os gestores municipais. Como resultado, percebemos que os custos de infraestrutura urbana são altos e podem interferi na gestão dos municípios. A pesquisa aponta ainda formas de minimizar esses custos através de diretrizes que norteiam o zoneamento e o uso do solo.

Palavras-chave: Custo de infraestrutura urbana; Gestão pública; Desenvolvimento.

\section{The cost of urban infrastructure: a design for the development of small municipalities}

The physical growth of the cities is related to the economic and demographic increase, which in turn, is related to the expansion of the urban perimeter through the dismemberment of rural areas such as the subdivisions. This growth generates a cost of urban infrastructure that can strongly reflect the public management and development of small municipalities. The research proposes to identify which are the systems of urban infrastructure that most impact in the budget of the management of the small municipalities. As method, we have documentary research, interview, budgeting, observation and technical survey. The technique of data analysis and interpretation sought to present a discussion of the data collected and the applicability of the study to the municipal managers. As a result, we realize that the costs of urban infrastructure are high and may interfere with the management of municipalities. The research also points out ways to minimize these costs through guidelines that guide zoning and land use.

Keywords: Cost of urban infrastructure; Public administration; Development.

Topic: Arquitetura e Urbanismo

Reviewed anonymously in the process of blind peer
Received: 20/12/2019

Approved: 14/02/2019

Anderson Saccol Ferreira (iD

Universidade do Oeste de Santa Catarina, Brasil

http://lattes.cnpq.br/4850843904897537

http://orcid.org/0000-0002-6237-9912

anderson.ferreira@unoesc.edu.br

Diogo Rafael do Nascimento (it)

Universidade do Oeste de Santa Catarina, Brasil

http://lattes.cnpq.br/9013441670449640

http://orcid.org/0000-0002-3254-6062

diogorafael2@hotmail.com

Referencing this:

FERREIRA, A. S.; NASCIMENTO, D. R.. O custo da infraestrutura urbana: um delineamento para o desenvolvimento de pequenos municípios. Engineering Sciences, v.8, n.1, p.67-79, 2020. DOI: http://doi.org/10.6008/CBPC2318-3055.2020.001.0008 


\section{INTRODUÇÃO}

As cidades correspondem a modificações quantitativas e qualificativas, sua evolução envolve transformações que norteiam seus espaços físicos sendo necessárias adaptações nesses espaços, principalmente em sua infraestrutura urbana. Na ótica de Zmitrowicz et al. (1997), o crescimento físico das cidades resulta principiante do crescimento econômico e demográfico, esses por sua vez se traduzem numa expansão de área por meio de loteamentos, edificações verticais habitacionais e indústrias. Os autores argumentam que essa expansão nas áreas já urbanizadas e construídas, resultam em renovações urbanas, os quais, as construções existentes são substituídas por outras, mais adequadas as novas atividades pretendidas nos locais (ZMITROWICZ et al., 1997).

Esses aspectos estão relacionados a gestão dos municípios que buscam a todo o momento desenvolver-se economicamente tornando-se mais competitivos nas suas atividades econômicas como prestação de serviços, indústria e comércio. A infraestrutura se torna um dos principais pontos que fazem aumentar a competitividade dos municípios. Mascaró et al. (2010) expõem que quanto melhor sua rede de infraestrutura, maior será a fluidez dos recursos econômicos, da mesma maneira, o município passa a ter áreas mais valorizadas, maior renda, melhorando a qualidade de vida. Além disso, existe um aumento do patrimônio municipal valorizando o espaço urbano, principalmente de regiões mais pobres que passam a serem servidas de redes de esgoto, água, drenagem e comunicação (ELOY et al., 2011).

Os sistemas de infraestrutura como o viário, água potável, esgoto sanitário, iluminação pública, energia elétrica, drenagem contribuem para a valorização imobiliária, diminuem a pobreza e auxiliam para o desenvolvimento de atividades econômicas. Os investimentos nas redes de infraestrutura urbana e rural devem ser feitos constantemente, sendo planejados e bem executados, de forma a não acarretarem problemas econômicos na gestão do município. Os custos de implantação e manutenção dessas redes costumam envolver orçamentos com valores elevados, que podem comprometer parte da renda municipal. Nessa ótica, a questão de pesquisa busca a avaliar quais são os custos de infraestrutura urbana e sua interferência na gestão pública de pequenos municípios?.

Como objetivo, a pesquisa pretende identificar quais são os sistemas de infraestrutura urbana que mais impactam no orçamento da gestão dos pequenos municípios e propor formas de minimizar esses custos. A pesquisa está estruturada por meio de técnicas da pesquisa documental, orçamentação, observação e do levantamento técnico. A técnica de análise e interpretação de dados buscou contemplar a pesquisa, apresentando uma discussão dos dados coletados e a aplicabilidade do estudo para os gestores municipais.

Como resultados, percebemos que os custos das redes de infraestrutura urbana são altos quando tratamos de municípios pequenos. Os resultados buscam formas de minimizar estes senário. Trazem por meio do procedimento metodológico dados relevantes acerca dos custos de implantação de novas infraestruturas urbanas e demostram que estes valores podem interferir na gestão dos municípios. A pesquisa aponta forma de minimizar esses custos por meio de diretrizes que norteiam o zoneamento e o uso 
do solo. Além dessa introdução a pesquisa está estruturada com a contextualização que traz o custo das redes de infraestrutura urbana em pequenos municípios, os procedimentos metodológicos e a análise dos resultados obtidos finalizando com as considerações finais.

\section{REVISÃO TEÓRICA}

\section{O custo da infraestrutura urbana em pequenos municípios}

O sistema de infraestrutura urbana pode ser definido a partir dos elementos que compõem o conjunto de instalações necessárias para as atividades humanas, como rede de esgoto, abastecimento de água potável, energia elétrica, coleta de águas pluviais, rede telefônica, vias públicas (ZMITROWICZ et al., 1997). Estes conjuntos de instalações visam proporcionar condições adequadas à moradia, ao trabalho, à saúde, ao lazer, à educação e à segurança (MASCARÓ, 2016). Já o sistema de infraestrutura urbana passa a ser classificado pelos elementos que o compõem e pelo princípio de funcionamento (MASCARÓ et al., 2005).

Nesse sentido, torna-se possível enfatizar os subsistemas de infraestrutura física urbana, compreendidos pelas redes de serviços e as redes de estrutura, que visam a distribuir os serviços. Os custos são diretamente influenciados pelo traçado, topografia e materiais utilizados, sendo a parte com o custo mais elevado do sistema. Se considera as ligações prediais, que permitem que as instalações de infraestrutura possam conectar-se com a rede de serviços. Esses custos são vinculados à forma em que as redes estão dispostas, bem como à distância para interligar as edificações. Têm-se os equipamentos complementares, individualizados, que se relacionam ao processo de provisão das infraestruturas (MASCARÓ, 2016).

Os custos de infraestrutura estão ligados diretamente a escolha do sítio tanto em áreas consolidadas quanto em espaços de expansão urbana. As áreas nas quais já constam edificações e alguns rudimentos de infraestrutura urbana podem ter seu custo superestimado, principalmente quando os locais onde o sítio instalado passa a necessitar de infraestruturas especiais, como grandes movimentações de terras, drenagens especiais, estabilização de taludes e bombeamento de água (SINAPI, 2018). Comumente, os custos são mais elevados quando se passa a ter sítios com inclinação elevada, inclinações médias de 20 a 30\%, consideradas fortes ou superior a $30 \%$, consideradas muito fortes (ROSS, 1994).

Para o Instituto de Pesquisas Tecnológicas - IPT (1991), o limite tecnicamente recomendável está em até $50 \%$ de inclinação, no entanto acarretará vultosos custos de infraestruturas. Cabe destacar que o município da pesquisa, não apresenta área urbanizada com inclinações superior a 50\%. Porém, não se pode desconsiderar, pois ambas as cidades possuem áreas com inclinação igual ou superior a 50\% e que podem futuramente ser transformadas em áreas urbanas, causando um aumento nos custos de infraestrutura urbana (MASCARÓ, 2016).

As áreas urbanizadas em locais afastados da infraestrutura central ou em locais com grandes inclinações, os empreendimentos como loteamentos terão seus custos elevados, bem como, os valores de manutenção destes locais, pois eles geram uma descontinuidade urbana. Estes equívocos, pela falta de planejamento criam desgastes e avultam os custos de manutenção para os cofres públicos. Grande parte das 
infraestruturas urbanas foram projetadas ao longo da década de 1970 e 1980, para suprir uma necessidade sem um planejamento em longo prazo, que na atualidade já se encontram saturadas, como vias, sistema de esgoto, energético drenagem e espaços verdes (ELOY et al., 2011).

Conforme destacam Mascaró et al. (2010), o sistema de água potável, quando no fim século XX, o consumo médio de água per capita circundava entre 10 a 20 litros diários, hoje fica em torno de 1.000 litros diários por pessoa. Esse aspecto passa a ser importante, pois a região em estudo está em constante crescimento, e tem demonstrado nos últimos anos, períodos de estiagem mais longos, ocasionando a falta de água, que passa a comprometer a agroindústria, como a geração de energia elétrica.

Já as redes de energia, em que era prevista 200 a 300 watts por pessoa, hoje atendem um consumo diário 100 vezes maior, devido ao alto grau de consumo em equipamentos elétricos e pelas facilidades do crédito fácil (MASCARÓ et al., 2010). O esgoto, antes coletado por um sistema de fossa séptica, filtro anaeróbio e sumidouro, atualmente já tem necessidades de implantação de redes de coleta de esgoto subterrâneas. Quanto às vias, essas foram projetadas para veículos leves, mas passam a receber veículos pesados, muitas vezes, com tráfego intenso. Têm-se os sistemas de drenagem, obsoletos com o aumento das áreas impermeabilizadas que passam a coletar toda a água das chuvas, e sem dar vazão, podendo ocorrer inundações.

Muitos desses problemas decorrentes da falta de planejamento urbano resultam em impactos ambientais com alto consumo dos recursos naturais, não sendo sustentável (MASCARÓ, 2016). Para que uma cidade consiga se desenvolver sustentavelmente, deverá alcançar um equilíbrio entre o que as pessoas necessitam e o que a natureza permite de alteração (SACHS, 1993). Dessa forma, a equidade entre os espaços urbanos, pessoas e natureza será alcançada melhorando a qualidade de vida de seus habitantes.

Quando se aborda a gestão da infraestrutura urbana passamos a um entendimento conceitual ligado aos custos e valores (MASCARÓ et al., 2005). O custo passa a ser uma atribuição que pode estar relacionado às despesas ao se adquirir um bem ou serviço. Já o valor associa-se à menor ou maior utilidade do bem ou serviço, podendo ser referido ao tempo, lugar ou finalidade (MOREIRA, 2001). Também podem ser considerados pela sua "[...] natureza, previsões sujeitas às incertezas e não podem ser determinados por fórmulas e cálculos" (ELOY et al., 2011).

Para o Departamento Nacional de Infraestrutura de Transportes - DNIT (2017), estes custos podem ser definidos pelos custos unitários de produção e de referência. Dessa forma, os custos unitários podem ser caracterizados pela execução de uma unidade de serviço. Os custos de produção são parâmetros técnicos acerca de várias operações nas quais se conhecem os serviços, quantidades, insumos e unidade de serviço (MOREIRA, 2001). Os custos de referência compõem os custos unitários de forma genérica, e os custos para orçamento compõem valores unitários que são orçados para uma obra específica, considerando condições locais (ELOY et al., 2011).

Dentro da gestão dos insumos de infraestrutura urbana temos custos distinguidos em diretos e indiretos. Os custos diretos são obtidos por meio dos quantitativos do projeto (MASCARÓ, 2016). Conforme destaca Dias (2006), os custos diretos estão relacionados com o produto em execução. Para Tisaka (2006), 
estes custos são a soma de todos os custos unitários dos serviços obtidos, bem como, da manipulação dos consumos e insumos sobre o preço de mercado, multiplicado pelas quantidades e somados com os custos de infraestrutura para a realização e execução dos trabalhos. Gadelha (2006) enfatiza que os custos para a gestão de infraestrutura compõem um conjunto de atividades relacionadas aos materiais, mão de obra, administração, consultorias, instalações, juros, impostos que compreendem uma relação direta com as quantidades.

Já os custos indiretos não integram os serviços, porém, são essenciais para sua obtenção, e assim, integram os custos produtivos (PARGA, 1995). Nesse sentido, o autor destaca que esses custos podem ser considerados como financiamentos e retenções de parte do valor das medições pelo contratante (PARGA, 1995). Segundo Dias (2006), os “[...] custos indiretos, são aqueles que não se relacionam diretamente com um produto ou parte dele, [...] devendo ser apropriados separadamente e imputados aos produtos através de métodos de rateio". Para Gadelha (2006), estes custos estão relacionados à totalidade do projeto que individualmente passa a não se relacionar com a duração da atividade, mas são proporcionais ao prazo de execução dos serviços passando assim, a serem descritos como custos indiretos.

Conforme destaca Mascaró et al. (2005), os custos diretos são os mais caros para a gestão urbana, sendo divididos em vários subsistemas conforme sua função. Nesse sentido, estas redes de infraestrutura devem estar adequadas e interligadas, ou seja, articuladamente ligadas entre si. As classificações das redes de infraestruturas passam a ser divididas conforme sua função, que podemos descrever como viário, sanitário, energético e de comunicação, onde todos eles impactam diretamente nos custos diretos para gestão urbana.

O sistema viário compreende uma das redes mais importantes de circulação, passando a receber os veículos e os pedestres, ela interliga os bairros, determina os eixos da cidade, ou seja, é responsável pela continuidade urbana regional (MASCARÓ, 2016). Este sistema ainda é complementado pela rede de drenagem pluvial e dessa forma, deve assegurar suas perfeitas condições em quaisquer intempéries climáticas. Todos os outros sistemas dependem do sistema viário, pois é a partir da abertura das vias que se implementam os sistemas de esgoto, água, energia e telecomunicações.

Segundo Mascaró et al. (2005), o sistema viário corresponde a uma grande fatia dos custos, chegando a $45 \%$ do total dos insumos urbanos. A pavimentação custa $73 \%$ e a drenagem $27 \%$ do total de infraestrutura do sistema viário, ocupando uma parcela importante do solo urbano cerca de 20 a 30\%. Uma vez implantado consiste em um dos sistemas que apresenta maior dificuldade dos gestores para se manter conservado.

Já o sistema sanitário compreende as redes de abastecimento de água e a rede de esgoto. Tais redes são importantes para as necessidades básicas de higiene. Elas correspondem a $20 \%$ dos custos de implantação da infraestrutura urbana, sendo 30\% de água potável e 70\% de esgoto cloacal (MASCARÓ et al., 2005). Quanto ao sistema energético, representado por duas redes, gás e energia elétrica, no qual o mais utilizado ainda é a rede elétrica, sendo que na região em estudo, não contempla rede de gás por tubulações, este ocorre por botijões ou por central de gás localizado na edificação. Por sua vez, a rede elétrica, fundamental para as áreas urbanas e rurais, passa a ser distribuída por um sistema que pode ser aéreo ou 
subterrâneo. A energia elétrica quando distribuída pelo nível aéreo (mais usual), tem sua problemática na distribuição que pode causar problemas de manutenção para gestão pública, inclusive para a implantação e manutenção adequados de um sistema de vegetação urbana, por sua restrição em relação ao porte.

A vegetação também pode acarretar aumento nos custos de manutenção do município (MASCARÓ, 2016). Interferências geralmente ocorrem com árvores, que plantadas incorretamente crescem e causam interrupções com queda de energia. Podem danificar as redes por interferência de ventos fortes que atingem a vegetação. É importante uma orientação técnica na escolha do tipo de vegetação, com estudo dos ventos predominantes. Portanto, merecem uma atenção por parte dos gestores, principalmente evitando futuros problemas, que podem necessitar reparos que envolvam grandes valores diretos ou indiretos aos consumidores.

Quando adotada rede a nível subterrâneo, os custos de manutenção são mais altos (MASCARÓ, 2016). Isso pelo nível de complexibilidade, pois essas dividem espaço com a rede de água, esgoto, pluvial e gás (se houver), e principalmente com as raízes da vegetação urbana. Seu processo de instalação pode criar "transtornos", pois é inevitável a destruição de calçadas, ruas e vegetação urbana (MASCARÓ et al., 2005).

Para a gestão dos municípios, o sistema energético tem um custo de implantação de $19 \%$ do total, sendo $58 \%$ para a energia elétrica e $42 \%$ para gás encanado (MASCARÓ et al., 2005). Cabe lembrar, que o sistema energético divide o espaço com o sistema de comunicação, composto por telefone, internet e televisão a cabo. Entre todos os sistemas citados, o sistema de comunicação é o que possui menor custo: 16\%, dividido entre 75\% telefonia e 25\% TV a cabo (MASCARÓ et al., 2005). Segundo Mascaró et al. (2005), "os custos totais dos quatro sistemas se situam entre 120 e 140 mil dólares por hectare urbanizado"

Esta estimativa dependerá do projeto urbano, do tamanho das vias, e principalmente da topografia (MASCARÓ, 2016). Não são consideradas as infraestruturas de grande porte, (metrô, viadutos, anéis rodoviários outros), destinadas a grandes áreas urbanizadas. No entanto, alguns aspectos podem ser analisados, pois são compatíveis com o município em estudo, como o modelo do sistema de abastecimento de água, rede de esgoto, sistema de coleta de lixo, pavimentação de vias públicas, pavimentação de passeios públicos, drenagem pluvial, redes de comunicação e espaços verdes.

É importante salientar que o espaço urbano é constituído pelas edificações, redes de infraestrutura, áreas livres e a vegetação urbana, todas relacionadas entre si. As redes de infraestrutura constituem uma pequena e importante parte do espaço urbano, pois elas possibilitam o seu uso, que se torna um elemento caracterizado pela sua forma, função e estrutura (MASCARÓ, 2016).

Os custos de implantação ou manutenção de qualquer uma das redes de infraestrutura urbana pode acarretar grande impacto na gestão financeira dos pequenos municípios, bem como, elas podem apresentar um conjunto fragmentado de catálogos incoerentes, os quais não articulam entre si, passando a gerar mais despesas ao município.

\section{METODOLOGIA}

Os procedimentos metodológicos adotados estão descritos como o cenário da pesquisa, a 
abordagem da pesquisa, o tipo de pesquisa, o método de pesquisa e as técnicas e instrumentos de coleta de dados, no qual destacamos a pesquisa documental, observação e o levantamento técnico. Para finalizar temos as técnicas de análise e interpretação de dados.

A pesquisa investiga o custo da infraestrutura urbana, um delineamento para desenvolvimento de pequenos municípios, como um suporte para os gestores públicos municipais. O estudo buscou uma abordagem qualitativa. Ela investiga seu significado por meio da percepção do fenômeno dentro do contexto, ou seja, o uso qualitativo procura captar o fenômeno e suas essências, procurando explicar sua origem, relações, mudanças e consequências (TRIVIÑOS, 1987). Como método de pesquisa adotamos o estudo de caso. Na ótica de Yin (2001), pode ser restrito em um ou vários municípios, podendo ser caracterizado como único ou múltiplo. $O$ estudo de caso parte de dois importantes pontos, caracterizados pela definição da teoria ou caracterização do problema, bem como, pela apresentação dos casos selecionados para definições dos indicadores de análise (YIN, 2001). Eles são importantes para o processo de coleta de dados e o desenvolvimento da pesquisa, onde cada estudo de caso deverá ser completo, com respectivos eventos, relevâncias e conclusões, apresentando as principais causas para que alguns fatos ocorram e outros não (OLIVEIRA, 2011). Dessa forma, o estudo de caso da pesquisa esteve direcionado para o município de Itá (SC), o qual, serviu como norteador para elaboração das preposições para o desenvolvimento de pequenos municípios, da mesma maneira que, proporcionou os parâmetros para a orçamentação acerca dos custos de infraestrutura urbana.

Abordamos nessa pesquisa um conjunto de instrumentos e técnicas de coleta de dados. Buscamos empregar diferentes técnicas para que se possa obter respostas de forma mais clara e objetiva (LAKATOS et al., 2007). A pesquisa se classifica como natureza aplicada, com objetivo descritivo podendo desenvolver as técnicas e procedimentos de coleta de dados da pesquisa documental, da observação e do levantamento técnico. Salientamos que a pesquisa documental busca investigar fatos registrados e dispersos pelo espaço em documentos como o Estatuto das Cidades, Plano Diretor, Código de Obras e o Zoneamento Uso e Ocupação do Solo. A observação e levantamento técnico exigem uma precaução e dedicação mais aguçada do pesquisador, pois busca os sentidos físicos a um amplo objeto para que dele extraia um claro e preciso conhecimento (OLIVEIRA, 2011). A observação é vital para estudo da realidade, "[...] à simples conjetura e simples adivinhação" (CERVO et al., 2002).

A técnica de coleta de dados a partir da observação consiste em utilizar e informar determinados aspectos da realidade. Ela permite, além de ver e ouvir, examinar fatos e fenômenos, que fazem parte deste estudo. Para Lakatos et al. (2007), a observação "é um elemento básico de investigação científica, utilizado na pesquisa de campo [...]", ela permite ao pesquisador alcançar e coligar fatos, que os indivíduos não possuem consciência, mas onde orientam seu comportamento. A observação é um elemento fundamental de coleta de dados, principalmente quando se buscamos levantar elementos das redes de infraestrutura urbana e Uso e Ocupação do Solo por atividades econômicas. Já o levantamento métrico e observação se deu pela localização e pelas atividades econômicas como indústrias, comércio e serviço, que estão inseridas, tanto no local como no entorno. A análise e interpretação de dados consiste em uma explicação dos dados 
coletados, onde se cumpre critérios científicos que dão credibilidade e validade à pesquisa (RICHARDSON, 1999). Segundo Bardin (1977), a análise e a interpretação dos dados dizem respeito ao tratamento dos resultados obtidos pelo pesquisador.

\section{RESULTADOS E DISCUSSÃO}

\section{A infraestrutura urbana e o delineamento para desenvolvimento de pequenos municípios}

Os sistemas de infraestrutura urbanas podem ser identificados pelos seus atributos e mesurados por portes. Descrevemos que a infraestrutura se trata de um conjunto de instalações necessárias as atividades humanas, sendo elas: pavimentação, rede de esgotos e de abastecimento de água potável, energia elétrica, coleta de águas pluviais, rede telefônica e gás canalizado (ELOY et al., 2011). Todas essas redes infraestrutura compõem um custo, de manutenção e instalação.

Segundo Cardoso (1993), o custo está ligado as despesas pagas para aquisição de um bem ou serviço. Sendo ele subjetivo, está associado a bem ou serviço (ELOY et al., 2011) e pode referir-se ao tempo ou a finalidade (MOREIRA, 2001) produzindo incertezas e previsões que não podem ser mesurados por formulas (ELOY et al., 2011). Os custos de uma obra de infraestrutura urbana são constituídos por insumos e pelos custos diretos e indiretos. Os custos diretos estão diretamente associados ao serviço que está sendo prestados, como insumos, mão de obra e equipamentos. Já os custos indiretos estão ligados a todo o custo que um orçamentista não consegue atribuir diretamente a um serviço.

Em obras de engenharia, o custo é determinado pelo método de orçamentação, onde é composto o custo unitário dos produtos. Para a obtenção dos custos quantificamos os insumos pela quantidade multiplicado pelo valor de referência do Sistema Nacional de Pesquisa de Custos e Índices da Construção Civil (2018). Esse custo é entendido como uma definição onde temos todos os insumos necessários para execução de uma obra compondo o preço final. O custo deverá conter, impostos, seguro, encargos sociais, mão de obra, insumos, lucro, margem de risco e o BDI - Benefícios e Despesas Indiretas. Essa composição quantificava orçamentária pode ser determinada pela equação:

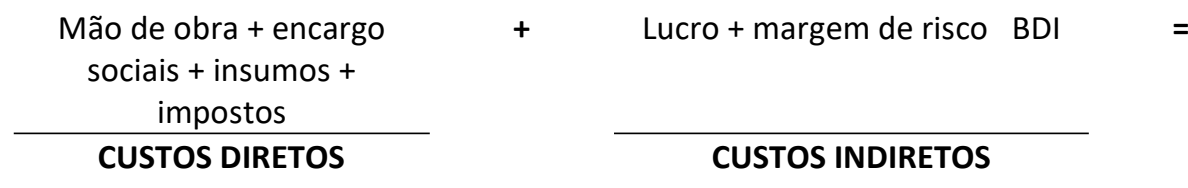

Total do orçamento

O resultado da somatória dos custos diretos e indiretos gera o valor total, sendo que o mesmo foi dividido pela área total orçada, gerando um valor por metro quadrado. Para esta composição de custo levantamentos uma via sem pavimentação do município de Itá (SC), com largura de 11 metros e extensão de 100 metros, conforme a Figura 1. Pelo método de orçamentação foi elaborado um quantitativo de custo de pavimentação, iluminação pública, sistema de água potável, drenagem e rede de esgoto doméstico. Os dados obtidos na orçamentação compõem o Sistema de Custos Rodoviários do DNIT - Departamento Nacional de Infraestrutura de Transportes, Sistema Nacional de Pesquisa de Custos e Índices da Construção Civil e do Sistema de Custos Rodoviários. Dessa forma, orçamos os serviços básicos conforme o levantamento 
técnico do trecho sem pavimentação para a pesquisa.

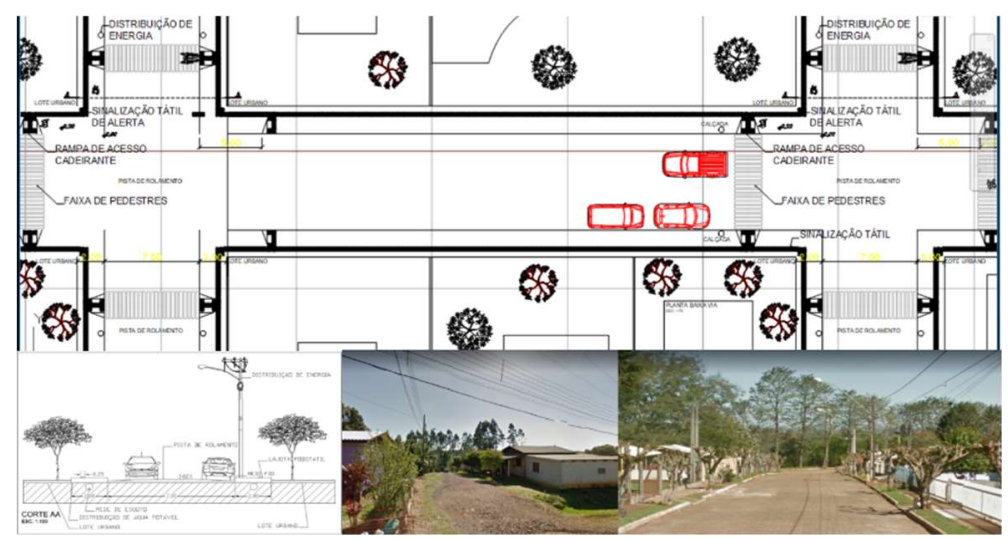

Figura 1: Projeto de via local com passeio público.

O trecho da análise contempla $1100 \mathrm{~m}^{2}$, a orçamentação gerou um valor de $\mathrm{R} \$ 243.265,00$ para a pavimentação asfáltica. Na drenagem o valor foi de $\mathrm{R} \$ 129.239,00$. O sistema de água e esgoto originou um valor de $R \$ 141.504,00$ e a iluminação um valor de $R \$ 141.768,00$ totalizando cerca de $R \$ 655.776,00$, ou seja $\mathrm{R} \$ 596,16$ o $\mathrm{m}^{2}$. Esses valores podem variar conforme o deslocamento dos insumos e mão de obra, da mesma maneira que a redução dos insumos e do uso de equipamento conforme o sítio e a proposta. Obtivemos o custo médio do passeio público. Este ficou entorno de $\mathrm{R} \$ 200,53$ o $\mathrm{m}^{2}$ de área para o município de Itá (SC). Consideramos a largura mínima dos passeios em vias púbicas com 1,5 metros numa extensão de 100 metros obtivemos $300 \mathrm{~m}^{2}$ de área a ser pavimentada num custo total de $\mathrm{R} \$ 60.159,00$. O Quadro 1 , apresenta o custo orçado conforme o projeto da Figura 1.

Quadro 1: Custo orçado conforme projeto apresentado.

\begin{tabular}{|l|l|l|}
\hline INFRAESTRUTURA & CUSTO TOTAL & $\mathrm{CUSTO} \mathrm{POR} \mathrm{M}^{2}$ \\
\hline Pavimentação asfáltica & $\mathrm{R} \$ 243.265,00$ & $\mathrm{R} \$ 221,15$ \\
\hline Drenagem & $\mathrm{R} \$ 129.239,00$ & $\mathrm{R} \$ 117,49$ \\
\hline Água e esgoto & $\mathrm{R} \$ 141.504,00$ & $\mathrm{R} \$ 128,64$ \\
\hline Iluminação & $\mathrm{R} \$ 141.768,00$ & $\mathrm{R} \$ 128,88$ \\
\hline Passeio público & $\mathrm{R} \$ 60.159,00$. & $\mathrm{R} \$ 200,53$ \\
\hline
\end{tabular}

Dessa forma, constatamos que a pavimentação das vias se torna o sistema de infraestrutura mais caro para ser implantado no município. Conforme apontam Mascaró et al. (2005), "os custos totais dos quatro sistemas se situam entre 120 e 140 mil dólares por hectare urbanizado". Percebemos que o custo médio, conforme o tipo de infraestrutura pode superar a 1 milhão de dólares por hectare urbanizado. Os resultados obtidos pela orçamentação podem interferir na gestão do município e devem ser desenvolvidas formas que possam minimizar este custo. A preposição para o desenvolvimento dos municípios está diretamente ligada aos seus sistemas de infraestrutura urbana. Os custos podem ser altos e para que ocorra a sustentabilidade municipal há necessidade de planejamento por meio de legislações especificas como Plano Diretor Municipal. Os municípios os quais não possuem planos devem construí-los pautados nas diretrizes na Lei 10.257 (BRASIL, 2001).

O zoneamento e o uso e a ocupação do solo urbano são ferramentas que podem minimizar os custos de infraestrutura urbana. O parcelamento do solo busca integrar correntemente os espaços de habitação, 
mobilidade, ambiental e as atividades econômicas. A organização espacial dos municípios permite a redução dos custos e investimentos localizados de infraestrutura urbana. $O$ uso de zonas mistas permite a integração de atividades econômicas e moradia, já as atividades industriais podem estar localizadas em corredores estratégicos como as rodovias, o qual permite maior visibilidade e transfere o transido de pesados para fora do município.

O planejamento da expansão do município permite conduzir conscientemente alternativas de desenvolvimento para o futuro. Conforme demostramos no Quadro 2, o município deverá legislar sobre a infraestrutura básica para o desmembramento e parcelamento do solo, ou seja, o quadro síntese apresenta uma preposição para os sistemas de infraestrutura para os novos loteamentos.

Quadro 2: Quadro síntese para preposição de infraestrutura para loteamentos.

\begin{tabular}{|c|c|c|}
\hline Infraestrutura & $\begin{array}{l}\text { Preposição para novos loteamentos } \\
\end{array}$ & Custo \\
\hline $\begin{array}{l}\text { Vias de circulação } 6 \text { a } 12 \\
\text { metros. }\end{array}$ & $\begin{array}{l}\text { Pouca circulação de veículos podendo ser em paralelepípedo, o que permite a } \\
\text { permeabilidade do solo e a diminuição da velocidade dos veículos. }\end{array}$ & Custo de manutenção baixo. \\
\hline $\begin{array}{l}\text { Vias de circulação } 12 \\
\text { metros ou superior. }\end{array}$ & $\begin{array}{l}\text { Muita circulação de veículos. Ruas com cobertura asfáltica. Prever sistemas de } \\
\text { redução de velocidade. Possibilidade de ligação de eixos estruturais da cidade } \\
\text { como a ligação das áreas residências com industriais. Deve-se planejar um } \\
\text { sistema de pavimentação para o tráfego de veículos pesados. }\end{array}$ & Custo de manutenção é alto. \\
\hline $\begin{array}{l}\text { Escoamento das águas } \\
\text { pluviais. }\end{array}$ & $\begin{array}{l}\text { O escoamento de águas pluviais deverá ser obrigatório para o } \\
\text { desmembramento e parcelamento do solo. Sua função permite que as aguas da } \\
\text { chuva possam ser deslocadas de forma segura para pontos estratégicos. A falta } \\
\text { desse sistema pode ocasionar enchentes e deslizamento de massa. Deve-se } \\
\text { prever formas de drenar a água sem contaminar os recursos naturais, } \\
\text { mantendo a qualidade do ar, corpos d'água, vegetação. }\end{array}$ & $\begin{array}{l}\text { Custo de manutenção e } \\
\text { implantação é alto. Previne } \\
\text { outros custos derivados desse } \\
\text { sistema. }\end{array}$ \\
\hline $\begin{array}{l}\text { Rede para o abastecimento } \\
\text { de água potável, energia } \\
\text { elétrica e iluminação } \\
\text { pública. }\end{array}$ & $\begin{array}{l}\text { O sistema de rede de água potável e energia elétrica deverá ser instalado sem } \\
\text { comprometer o abastecimento das demais instalações já existentes. A } \\
\text { iluminação pública deverá estar presente em as vias de forma a reduzir a } \\
\text { criminalidade. }\end{array}$ & $\begin{array}{l}\text { Custo de manutenção e } \\
\text { implantação é alto. }\end{array}$ \\
\hline $\begin{array}{l}\text { Esgotamento sanitário } \\
\text { domiciliar }\end{array}$ & $\begin{array}{l}\text { O município deverá legislar e regulamentar por lei formas de minimizar os } \\
\text { impactos ambientais acerca do esgotamento sanitário domiciliar. O uso do } \\
\text { sistema de Fossa séptica, filtro anaeróbio e sumidouro poderá ser adotado } \\
\text { desde que ocorra a fiscalização e manutenção do sistema, tornando-o mais } \\
\text { eficiente. }\end{array}$ & $\begin{array}{l}\text { Sem custo quando optado } \\
\text { pelos sistemas de Fossa } \\
\text { séptica, filtro anaeróbio e } \\
\text { sumidouro. }\end{array}$ \\
\hline Sistema de monitoramento & $\begin{array}{l}\text { O sistema de monitoramento tende a auxiliar as vias, criando espaços mais } \\
\text { seguros e controlados. }\end{array}$ & Custo alto para manutenção. \\
\hline Passeio público & $\begin{array}{l}\text { O passeio público deverá ser obrigatório para loteamento novos, pois garante a } \\
\text { acessibilidade em todos os locais do município. Deve-se criar diretrizes que } \\
\text { possibilitem a obrigatoriedade do passeio em todas as ruas do município. }\end{array}$ & $\begin{array}{l}\text { Sem custo para o município. } \\
\text { Responsabilidade do } \\
\text { proprietário do lote. }\end{array}$ \\
\hline Áreas de uso coletivo & $\begin{array}{l}\text { Para cada novo loteamento deve-se respeitar um percentual de } 30 \% \text { destinado } \\
\text { as áreas de uso coletivo, como as vias, os passeios, as praças, os parques e as } \\
\text { áreas para futura implantação de equipamento públicos. }\end{array}$ & Custo alto para manutenção. \\
\hline
\end{tabular}

A legislação flexível do parcelamento do solo permite a redução dos custos e o aumento da oferta de lotes urbanos e unidades habitacionais (BRASIL, 2001). A verticalização das edificações aumenta a densidade populacional por metro quadrado permitindo o melhor uso das redes de infraestrutura. Esse aumento da verticalização deverá ocorrer de forma consciente, sem prejuízos a qualidade de vida. Os indicados de ocupação do solo devem permitir a permeabilidade da água em pelo menos $10 \%$ da área do lote. Outras formas de permeabilidade da água no solo devem ser criadas por meio das vias, dos passeios e equipamentos públicos, como praças e parques. O traçado da malha de novos loteamentos deve facilitar a circulação interna, mantendo sempre o princípio da sustentabilidade, predominando a qualidade de vida dos habitantes. A criação de lugares que permitam a interação entre a vizinhança poderá possibilidade o cuidado dos espaços como canteiro central e passeios. Dessa forma, diretrizes sobre espécies de vegetações devem ser criadas para proporcionar uma diversidade de espécies sem que causem prejuízos para os sistemas de 
infraestrutura.

A adoção espontânea de áreas, praças, parques, canteiros centrais, rótulas e passeios públicos. Permite criar lugares de interação, minimiza os custos de infraestrutura e mantem a cidade mais viva. A adoção da cidade pelos seus habitantes poderá contribuir para minimizar os investimentos dos gastos de seus sistemas de infraestrutura, melhorando a qualidade de vida de seus habitantes. Outros instrumentos que devem ser adotados como mecanismo para a redução dos custos são: o Imposto Predial Territorial Urbano - IPTU progressivo no tempo, que visa diminuir a descontinuidade da malha urbana e combater os vazios urbanos. A desapropriação com pagamento em títulos, tem como princípio complementar o IPTU Progressivo no tempo, pois após cinco anos da cobrança do IPTU o proprietário que não tenha cumprido a obrigação de construção e ocupação da área ou edificação o município poderá desapropriar o imóvel, com pagamento em títulos da dívida pública (BRASIL, 2001).

Já a outorga onerosa do direito de construir, concede ao município a contrapartida a ser prestada pelo beneficiário pela aquisição da cota máxima de construção. Esse recurso deverá ser investido na regularização fundiária, na execução de programas e projetos habitacionais de interesse social, no ordenamento e direcionamento da expansão urbana, na criação de espaços públicos de lazer e áreas verdes ou na proteção de áreas de interesse histórico, cultural ou paisagístico (BRASIL, 2001).

As operações urbanas consorciadas permitem ao município um conjunto de intervenções e medidas, as quais, serão coordenadas pelo Poder Municipal, contendo a participação dos proprietários, moradores e usuários. Os investimentos podem ser do setor privado e público, com o objetivo de transformar urbanisticamente a área da intervenção permitindo melhoria social e valorização ambiental. Um dos principais instrumentos urbanístico que pode reduzir o custo dos sistemas de infraestrutura é o estudo de impacto de vizinhança. Esse estudo prévio, permite ao município um controle mais eficaz das atividades dos efeitos positivos e negativos de atividades no perímetro urbano. Seus mecanismos previnem a super utilizar os sistemas de infraestrutura. Por meio dele, é possível prever o a adensamento populacional, uso e ocupação do solo, a valorização imobiliária a geração de tráfego e demanda por transporte público e a alteração da paisagem urbana.

Por fim, só será possível prepor formas de minimizar os custos de infraestrutura urbana nos pequenos municípios se os mesmos obtiverem Planos Diretores. Percebemos que não há como planejar o desenvolvimento municipal se não for elaborado as diretrizes de planejamento, que preveem o uso e a ocupação do solo urbano e seu zoneamento. A organização geográfica do município permite minimizar os custos de implantação e manutenção dos sistemas, além de facilitar ao gestor o planejamento dos investimentos a curto, médio e longo prazo.

\section{CONCLUSÕES}

A pesquisa teve como objetivo identificar quais são os sistemas de infraestrutura urbana que mais impactam no orçamento da gestão dos pequenos municípios. A questão de pesquisa buscou avaliar os custos de infraestrutura que mais interferem na gestão de pequenos municípios. Constatamos que o sistema viário 
é o mais caro e interfere diretamente com custo elevados para a gestão pública. $\mathrm{O}$ objetivo da pesquisa foi entendido na integra propondo alternativas para minimizar os custos por meio da criação e da elaboração de planos diretores.

Segundo Zmitrowicz et al. (1997), o crescimento físico dos municípios resulta no crescimento econômico e demográfico aumentando o número de loteamentos edificações verticais habitacionais e indústrias. Nesse contexto, o estudo prevê formas de minimizar esses custos e a super utilização dos sistemas de infraestrutura urbana.

A pesquisa aponta uma preposição para minimizar os sistemas de infraestrutura dos loteamentos novos por meio de vários instrumentos como o zoneamento, o uso e ocupação a outorga onerosa do direito de construir e o IPTU progressivo no tempo. Quando Mascaró et al. (2010), apontam que as melhorias da rede de infraestrutura urbana geram mais mobilidade e valorização das áreas melhorando a qualidade de vida, propomos a adoção espontânea de áreas, parques, praças, canteiros centrais, rotulas e dos passeios públicos permitindo criar lugares de interação entre a vizinhança mantem a cidade mais viva. Salientamos que os resultados obtidos buscam minimizar os custos das redes de infraestrutura urbana, proporcionando melhorarias aos municípios. O estudo aponta um custo relativamente alto para os gestores, pincipalmente em município, os quais possuem menos de $50 \%$ de vias pavimentadas.

Constatamos que os resultados obtidos podem minimizar os custos criando formas sustentáveis para o gestor gerenciar o planejamento urbano, proporcionando o crescimento e o desenvolvimento de todo o território urbano. Salientamos, que só terá eficácia se o município possuir um conjunto de leis e diretrizes que regulamentem o zoneamento e o uso e ocupação do solo urbano. A pesquisa contribui apontando o sistema de infraestrutura urbana mais caro e propondo formas de minimizar esse custo. Além disso, ela demostra outros custos que podem interferir na acessibilidade como o passeio público e na super utilização dos sistemas já existente. Apresenta formas por meio da criação de diretrizes urbanísticas para minimizar estes custos.

O estudo está limitado apenas num estudo de caso do município de Itá (SC), onde encontramos 95\% de ruas já pavimentadas. Torna-se importante realizar esse estudo com município que ainda não possuam o Plano Diretor em vigor. A orçamentação, limita-se a um estudo quantitativo de uma determinada área, assim, é relevante a realização da orçamentação com outros sistemas de pavimentação prevendo uma cobertura mais barata. Recomendamos para futuros estudos a ampliação e aplicação das preposições de delineiam formas de economizar com os custos de infraestrutura urbana.

\section{REFERÊNCIAS}

BARDIN, L.. Análise de conteúdo. Lisboa: Edições 70, 1977.

BRASIL. Lei n. 10.257, de10 de Julho de 2001. Regulamenta os ARTs. 182 e 183 da Constituição Federal. Brasília: DOU, 2001.

CERVO, A. L. BERVIAN, P. A.. Metodologia científica. 5 ed. São Paulo: Prentice Hall, 2002.
DIAS, L.. Redes: emergência e organização. In: Geografia: Conceitos e Temas. 3 ed. Rio de Janeiro: Bertrand Brasil, 2006.

ELOY, E. J. S.; CARDOSO, L. R. A.. Parâmetros e conceitos dos custos de infraestrutura em uma cidade média. São Paulo: EPUSP, 2011

GADELHA, L. G. C.. Orçamento na construção pesada. 
Recife: Bagaço, 2006.

IPT. Instituto de Pesquisas Tecnológicas. Manual de ocupação de encostas. São Paulo: USP, 1991.

LAKATOS, E. M.; MARCONI, M. A.. Técnicas de pesquisa. 6 ed. São Paulo: Atlas, 2008.

MASCARÓ, J. L.; AZAMBUJA, G. B.. Sustentabilidade em urbanizações de pequeno porte. Porto Alegre: Masquatro, 2010.

MASCARÓ, J. L. Infraestrutura urbana para o século XXI. Porto Alegre: Masquatro, 2016

MASCARÓ, J. L.; YOSHINAGA, M.. Infraestrutura urbana. Porto Alegre: Masquatro, 2005.

MOREIRA, D. A.. Administração da produção e operações. Boston: Thomson Learning, 2001.

OLIVEIRA, M. F.. Metodologia científica: um manual para a realização de pesquisas em Administração. Catalão: UFG, 2011.

PARGA, P.. Cálculo do preço de venda na construção civil. São Paulo: Pini, 1995.
RICHARDSON, R. J.. Pesquisa social: métodos e técnicas. 3 ed. São Paulo: Atlas, 1999.

ROSS, J. L. S.. Análise empírica da fragilidade dos ambientes naturais e antropizados. Revista do Departamento de Geografia FFLCH/USP, v.8, p.63-74, 1994.

SACHS, I.. Estratégias de transição para o século XXI. In: BURSZTYN, M.. Para pensar o Desenvolvimento Sustentável. São Paulo: Brasiliense, 1993.

SINAPI. Sistema Nacional de Pesquisa de Custos e Índices da Construção Civil. Metodologia de elaboração e manutenção dos Orçamentos de Referência. SINAPI, 2018.

TISAKA, M.. Orçamento na construção civil: Consultoria, Projeto e Execução. São Paulo: Pini. 2006

TRIVIÑOS, A. N. S.. Introdução a pesquisa em ciências sociais: a pesquisa qualitativa em educação. São Paul: Atlas, 1987.

YIN, R. K.. Estudo de caso: planejamento e métodos. 5 ed São Paulo: Bookman, 2001.

ZMITROWICZ, W; ANGELIS NETO, G.. Infraestrutura urbana. São Paulo: Texto Técnico, Escola Politécnica da Universidade de São Paulo, 1997.

A CBPC - Companhia Brasileira de Produção Científica (CNPJ: 11.221.422/0001-03) detém os direitos materiais desta publicação. Os direitos referem-se à publicação do trabalho em qualquer parte do mundo, incluindo os direitos às renovações, expansões e disseminações da contribuição, bem como outros direitos subsidiários. Todos os trabalhos publicados eletronicamente poderão posteriormente ser publicados em coletâneas impressas sob coordenação da Sustenere Publishing, da Companhia Brasileira de Produção Científica e seus parceiros autorizados. Os (as) autores (as) preservam os direitos autorais, mas não têm permissão para a publicação da contribuição em outro meio, impresso ou digital, em português ou em tradução. 